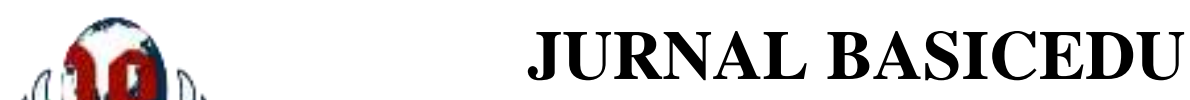

Volume 5 Nomor 5 Tahun 2021 Halaman 4138 - 4145

Research \& Learning in Elementary Education https://jbasic.org/index.php/basicedu

\title{
Strategi Hubungan Masyarakat (Public Relation) dalam Peningkatan Pemasaran Lembaga Pendidikan
}

\author{
Suyitno \\ STIE Indonesia Malang, Indonesia \\ E-mail: drsuyitno@yahoo.co.id
}

\begin{abstract}
Abstrak
Penelitian ini bertujuan untuk mengetahui strategi hubungan masyarakat dalam meningkatkan pemasaran di lembaga pendidikan. Penelitian ini dilakukan dengan pendekatan penelitian deskriptif kualitatif dan menggunakan rancangan studi kasus serta data-data dikumpulkan dengan observasi partisipatif, wawancara mendalam, dan dokumentasi, selanjutnya dianalisis dengan model interaktif. Hasil penelitian menunjukkan bahwa strategi hubungan masyarakat MAN 2 Tulungagung meliputi pertama strategi dalam pemetaan pasar (segmentation) untuk meningkatkan pemasaran lembaga pendidikan dengan mempertimbangkan segmen emosional dan segmen geografis. Kedua, strategi dalam penentuan target (targeting) untuk meningkatkan pemasaran lembaga pendidikan meliputi dilakukan dengan dua pilihan yakni dengan kualifikasi akademik yang baik dengan spesialisasi selektif dan kualifikasi khusus. Ketiga, strategi dalam penentuan posisi pasar (positioning) dengan membangun kepercayaan masyarakat dengan mempublikasikan deferensiasi programprogram unggulan serta prestasi-prestasi yang diraih sehingga akan meningkatkan citra madrasah.
\end{abstract}

Kata Kunci: Strategi, Hubungan Masyarakat, Pemasaran Lembaga Pendidikan

\begin{abstract}
This study aims to determine the public relations strategy in improving marketing in educational institutions. This research was conducted with a qualitative descriptive research approach with a case study design and the data were collected by participatory observation, in-depth interviews, and documentation, then analyzed using an interactive model. The results showed that the public relations strategy of MAN 2 Tulungagung includes the first strategy in market segmentation mapping to improve the marketing of educational institutions by considering the emotional segment and geographical segment. Second, the strategy in targeting to increase the marketing of educational institutions includes two choices, namely with good academic qualifications with selective specialization and special qualifications. Third, the strategy in determining positioning by building public trust by publishing the differentiation of superior programs and achievements so that it will improve the image of the madrasa.
\end{abstract}

Keywords: Strategy, Public Relations, Marketing of Educational Institutions

Copyright (c) 2021 Suyitno

Corresponding author :

Email : drsuyitno@yahoo.co.id

DOI : https://doi.org/10.31004/basicedu.v5i5.1480

ISSN 2580-3735 (Media Cetak)

ISSN 2580-1147 (Media Online)

Jurnal Basicedu Vol 5 No 5 Tahun 2021

p-ISSN 2580-3735 e-ISSN 2580-1147 


\section{PENDAHULUAN}

Pendidikan adalah kebutuhan setiap warga negara dan pemerintah bertanggung jawab untuk menyediakan pendidikan yang berkualitas bagi warganya. Untuk sebagian besar pemerintah telah gagal dalam melaksanakan tugasnya sehingga para pemain swasta telah muncul untuk menyelamatkan. Seiring dengan perkembangan zaman, saat ini banyak lembaga-lembaga pendidikan tumbuh di tengah-tengah masyarakat. Tapi pemain swasta menginginkan keuntungan, sehingga muncul perdebatan tentang pertimbangan pendidikan sebagai barang publik atau barang pribadi (Khan, 2017). Masing-masing lembaga baik negeri atau swasta saling berkompetisi untuk menarik perhatian masyarakat. Sehingga saat ini masyarakat memilki banyak pilihan ketika akan menyekolahkan anggota keluarganya. Salah satu pertimbangan masyarakat dalam menentukan pilihan lembaga pendidikan adalah citra, image, atau reputasi suatu lembaga pendidikan. Melihat fenomena saat ini, sebesar apapun institusi yang beroperasi disektor jasa, jika tidak diperkenalkan kepada masyarakat, maka lembaga pendidikan tidak akan berkembang. Sehingga untuk mencapai tujuan tersebut diperlukan manajemen pemasaran jasa pendidikan yang baik diperlukan untuk menarik minat siswa pada tahun ajaran yang akan datang dan pembentukan sikap positif citra bagi institusi (Faridhoh et al., 2020).

Pemasaran untuk institusi pendidikan adalah mutlak diperlukan karena lembaga pendidikan perlu meyakinkan masyarakat dan pelanggan tentang layanan pendidikan (siswa, orang tua, dan pihak terkait lainnya) yang masih dimiliki sekolah keberadaannya, maka pelayanan pendidikan yang diselenggarakan lembaga pendidikan relevan dengan kebutuhan pelanggan jasa pendidikan (Paula, 2019; Rajkumar et al., 2021). Di sinilah hubungan masyarakat (humas) sekolah memiliki peran penting untuk membangun dan mempertahankan citra positif sehingga lembaganya dapat memikat hati masyarakat. Hal ini tidak hanya berlaku pada sekolah negeri milik pemerintah saja, tetapi juga sekolah swasta. Bahkan sekolah swasta cenderung lebih aktif dalam mempromosikan keunggulan sekolahannya kepada masyarakat, sehingga bagi sekolah berstatus negeri apalagi yang difavoridkan tidak boleh terlena karena sudah merasa mapan.

Hubungan masyarakat memiliki posisi penting dalam suatu organisasi. Hubungan masyarakat atau yang sering dikenal dengan sebutan humas memiliki keterlibatan terhadap keberadaan, kelangsungan, bahkan kemajuan suatu lembaga atau organisasi, begitu juga dalam lembaga pendidikan. Sesuai dengan namanya, humas adalah sebagai corong lembaga dan bertanggung jawab dalam membangun komunikasi yang baik antar lembaga pendidikan (pihak internal) dengan pihak eksternal lembaga atau masyarakat. Wardaya, (2016) mengemukakan bahwa komunikasi yang baik antar pihak internal lembaga dengan pihak eksternal akan dapat membangun kepercayaan masyarakat. Hal ini menjadi penting mengingat salah satu faktor maju tidaknya suatu lembaga pendidikan adalah keterlibatan dan kepercayaan masyarakat. Masyarakat yang terlibat aktif dalam lembaga pendidikan akan dapat memberikan pengaruh dan berbagai masukan yang dapat dipertimbangkan untuk memajukan lembaga pendidikan. Adapaun kepercayaan masyarakat akan meningkatkan pelanggan pendidikan.

Hubungan sekolah dan masyarakat dilakukan untuk menjembatani kebutuhan yang dibutuhkan oleh sekolah dan masyarakat, sekolah melakukan komunikasi dengan masyarakat agar memahami kebutuhan pendidikan dan pembangunan masyarakat. Hubungan sekolah dan masyarakat dapat dikatakan untuk menjaga dan mengembangkan saluran informasi dua arah yang efisien serta saling pengertian antara sekolah, personil sekolah, dan anggota masyarakat. Humas di sekolah adalah proses mengungkapkan aspek-aspek terbaik dari sekolah dan menerima pesan positif untuk mendapatkan dukungan dari masyarakat (P \& Andriyani, 2020; Çoruk, 2018; Immelman \& Roberts-Lombard, 2015). Berdasarkan pendapat tersebut hubungan sekolah dan masyarakat akan tercipta dengan baik apabila terdapat komunikasi dua arah dan saling pengertian antara pihak sekolah dengan masyarakat dan berusaha untuk memenuhinya, maka akan tercipta kepercayaan masyarakat terhadap sekolah tersebut. Sebagai timbal balik, masyarakat terutama calon wali murid akan memasukkan putra putrinya ke sekolah yang mereka percaya. 
Public relations dalam dunia pendidikan adalah proses komunikasi dua arah yang terencana dan sistematis antara organisasi pendidikan dengan lingkungan internal dan eksternal organisasi untuk membangun nilai, ketertarikan, pemahaman, dan dukungan terhadap organisasi tersebut. Public relations atau humas adalah gerbang terdepan yang menghubungkan lingkungan internal lembaga atau organisasi dengan public atau masyarakat. Humas juga disebut-sebut sebagai corong suatu lembaga yang memiliki fungsi sebagai media penyalur informasi. Humas memiliki tanggungjawab membangun komunikasi internal maupun eksternal (P \& Andriyani, 2020).

Selain itu juga memilih target pemasaran yaitu sekolah-sekolah setingkat dibawahnya yang unggul, dan menciptakan daya saing lembaga dengan membangun kerjasama baik dengan internal maupun eksternal lembaga. Hal-hal tersebut tentunya menjadi suatu keunggulan yang dapat dipromosikan, menjadi daya saing tersendiri bagi lembaga dan dipasarkan kepada masyarakat sebagai pemasaran lembaga, sekaligus bentuk nyata dalam upaya memberikan layanan pendidikan yang terbaik, sehingga mendapat simpati masyarakat. Tentunya hal tersebut tidak bisa terlepas dari peran pokok dari hubungan masyarakat atau humas pada lembaga pendidikan tersebut dalam memanfaatkkan unsur strategi pemasaran sehingga dapat meningkatkan pemasaran lembaga pendidikan. Dalam penelitian ini, peneliti fokus pada strategi humas dalam meningkatkan pemasaran lembaga pendidikan yang melibatkan unsur strategi pemasaran yaitu segmentation, targeting, dan positioning untuk meningkatkan pemasaran lembaga pendidikan yang ada di MAN 2 Tulungagung.

\section{METODE}

Penelitian ini menggunakan desain penelitian kualitatif dengan jenis studi kasus. Lokasi penelitian di MAN 2 Tulungagung diambil dengan kriteria keunikan dan keberhasilan dalam strategi pemasaran lembaga pendidikan. Pengambilan sampel informan dilakukan dengan menggunakan purposive sampling dan didukung dengan teknik snowball sampling dan diperoleh 13 informan antara lain kepala madrasah, wakil kepala madrasah bidang kesiswaan dan hubungan masyarakat, 4 orang tokoh masyarakat, 5 orang guru MAN 2 Tulungagug, 4 orang wali murid MAN 2 Tulungagung. Dalam penelitian ini instrumen penelitian yang utama adalah peneliti sendiri sehingga mewajibkan kehadiran peneliti di lokasi penelitian, setelah fokus penelitian menjadi jelas maka dikembangkan instrumen penelitian sederhana. Penelitian ini dilakukan selama 3 bulan dan pengumpulan data dilakukan dengan wawancara, observasi, dan dokumentasi. Wawancara dilakukan dengan menggunakan indepht interview kepada informan. Observasi dilakukan dengan observasi partisipatif terutama pada observasi terfokus setelah observasi deskriptif dan selektif. Untuk melengkapi analisis, dibuat ringkasan kontak dokumen yang diperoleh dari catatan lapangan dan ringkasan kontak observasi. Selama pengumpulan data transkrip, pengkodean, dan meringkas kontak wawancara dikelola. Reduksi data dilakukan dengan tujuan memperhatikan fokus penelitian. Data dianalisis dengan menggunakan model analisis interaktif seperti yang disarankan Miles dan Huberman dalam Suyitno (2018). Untuk memastikan keabsahan, data diuji dengan persyaratan kredibilitas, konfirmabilitas, kebergantungan, dan transferabilitas. Pemeriksaan kredibilitas dilakukan dengan menggunakan triangulasi sumber dan teknik serta pemeriksaan anggota. Ketergantungan dan kepastian data diperiksa dengan menggunakan audit proses. Untuk memastikan transferbilitas, kajian ini keotentikan data dibuat sistematis dan memiliki kemampuan dipahami oleh semua pihak.

\section{HASIL DAN PEMBAHASAN}

Saat ini orang orang mengalami pendidikan sebagai sebuah corporate, yaitu lembaga pendidikan disebut sebagai organisasi produksi yang menghasilkan jasa pendidikan yang dibeli sebagai lembaga yang memberikan layanan jasa pendidikan kepada siswa, mahasiswa, ataupun masyarakat umum. Oleh karena itu, 


\section{Strategi Hubungan Masyarakat (Public Relation) dalam Peningkatan Pemasaran Lembaga Pendidikan - Suyitno \\ DOI: https://doi.org/10.31004/basicedu.v5i5.1480}

pihak sekolah/madrasah harus mengembangkan strategi pemasarannya agar mutu lembaga pendidikannya semakin meninkat dan dapat menarik banyak siswa. Karena, etika pemasaran dalam dunia pendidikan adalah menawarkan mutu layanan intelektual dan pembentukan watak secara menyeluruh.

Segmentasi pasar adalah membagi pasar menjadi kelompok pembeli yang dibedakan berdasarkan kebutuhan, karakteristik, atau tingkah laku, yang mungkin membutuhkan produk yang berbeda. Sedangkan positioning adalah karakteristik dan pembedaan (diferensiasi) produk yang nyata dan memudahkan konsumen untuk membedakan produk jasa antara satu lembaga dengan lembaga lainnya. Dalam pasar yang sangat beragam karakternya, perlu ditentukan atribut-atribut apa yang menjadi kepentingan utama bagi pengguna pendidikan. Secara umum, pasar dapat dipilah berdasarkan karakteristik demografi, geografi, psikografi, maupun perilaku. Dengan demikian, sekolah akan lebih mudah menentukan strategi pemasaran sehubungan dengan karakteristik dan kebutuhan pasar. Setelah diketahui karakter pasar, maka akan menentukan bagian pasar mana yang akan dilayani.

Pemetaan pasar (segmentasi) yang dilakukan oleh bidang Hubungan Masyarakat (Humas) di MAN 2 Tulungagung mempertimbangkan faktor emosional dan geografis. Pemetaan pasar yang didasarkan faktor emosional, dilakukan oleh humas MAN 2 Tulungagung utamanya dengan pertimbangan religiusitas dan ikatan alumni. Pertimbangan religiusitas dilakukan oleh Humas MAN 2 Tulungagung didasarkan atas kesadaran bahwa MAN 2 Tulungagung merupakan lembaga pendidikan formal berbasis Islam maka lembagalembaga yang menjadi sasaran antara lain lembaga pendidikan yang dikelola oleh pondok pesantren dan lembaga pendidikan Islam lainnya. Pondok-pondok pesantren yang cukup besar dan telah mengelola pendidikan formal baik Madrasah Tsanawiyah (MTs) maupun Sekolah Menengah Pertama (SMP) di kawasan Tulungagung dianggap sebagai pasar utama bagi MAN 2 Tulungagung. Pertimbangan yang kedua dari faktor emosional adalah ikatan alumni. Alumni sebagai bagian penting dari sebuah lembaga pendidikan dimana dihasilkan, tidak lepas dari keberadaannya yang dapat menentukan eksistensi dan kualitas dari lembaga pendidikan yang bersangkutan. Hal ini mengindikasikan bahwa keberadaan alumni seharusnya dapat dijadikan kriteria keberhasilan sebuah lembaga pendidikan dalam mencetak produk lulusan yang berkualitas dan berdaya saing tinggi konsern terhadap keberadaan alumninya. Bidang Humas MAN 2 Tulungagung secara periodik setiap tahun mengundang IAMANTUL 2 (Ikatan Alumni MAN Tulungagung 2), dimana tujuannya selain sebagai sarana silaturahmi juga menerima masukan dari para alumni. Para alumni tersebut juga dimanfaatkan untuk "menyebar kabar baik" kepada masyarakat sehingga akan meningkatkan animo terhadap pendaftaran calon siswa baru di MAN 2 Tulungagung.

Selanjutnya Humas MAN 2 Tulungagung melakukan pemetaan pasar berdasarkan segmen geografis. Sekolah, terutama sekolah negeri hanya dapat melakukan segmentasi pasar terbatas pada radius terdekat dengan sekolah saja, misalnya satu kecamatan. Hal itu berdasarkan Peraturan Menteri Pendidikan dan Kebudayaan Republik Indonesia Nomor 17 Tahun 2017 (salinan PPDB 2017.Pdf, n.d.) menegaskan siswa diprioritaskan dapat diterima di sekolah yang berada di radius terdekat dengan tempat tinggalnya. Dengan demikian, sekolah negeri tidak dapat menetapkan target pada segmen siswa secara luas. Persaingan dalam rekrutmen siswa baru di Kabupaten Tulungagung cukup tinggi, apalagi dalam upaya peningkatan kualitas lembaga pendidikan MAN 2 Tulungagung yang pada akhirnya memperoleh predikat "sekolah favorit" merupakan langkah tersendiri utamanya untuk memperoleh calon siswa baru yang berkualitas. Oleh sebab itu, Humas MAN 2 Tulungagung berusaha menjangkau daerah pemasaran yang luas hingga keluar Kabupaten Tulungagung, antara lain Kabupaten Trenggalek dan Kabupaten Kediri. Dipilihnya daerah-daerah tersebut sebagai segmen geografis dalam pemasaran lembaga pendidikan MAN 2 Tulungagung yakni dengan mempertimbangkan adanya persamaan pengembangan kurikulum pondok-pondok pesantren besar di wilayah tersebut dengan unit kegiatan kokurikuler dan ekstrakurikuler di MAN 2 Tulungagung.

Segmentasi merupakan hal pertama yang harus dilakukan oleh sekolah/madrasah untuk mencapai hasil yang optimal. Segmentasi pasar bisa diklasifikasi berdasarkan pembagian wilayah (segmentasi geografi). 


\section{Strategi Hubungan Masyarakat (Public Relation) dalam Peningkatan Pemasaran Lembaga Pendidikan - Suyitno \\ DOI: https://doi.org/10.31004/basicedu.v5i5.1480}

Segmentasi pasar yang dilakukan oleh Humas MAN 2 Tulungagung dengan mempertimbangkan segmen emosional dan segmen geografi menjadi acuan dalam pola pemasaran lembaga pendidikan MAN 2 Tulungagung dalam mencapai sekolah favorit. Dalam kaca mata marketing, lembaga pendidikan Islam termasuk dalam segmen pasar emosional. Maksud segmen pasar emosional adalah kumpulan pelanggan atau "nasabah" yang datang mendaftar atau bergabung ke sebuah lembaga pendidikan (sekolah) karena pertimbangan religiousitas dan kurang memperhatikan harga, kualitas, mutu dan ketersediaan jaringan (networking) yang memadai (Immelman \& Roberts-Lombard, 2015). Sedangkan terkait segmen geografi, Hemsley-Brown (2016); Kartikasari, (2017) mengungkapkan bahwa segmentasi pasar pada dasarnya merupakan kegiatan mengklasifikasikan pasar yang heterogen menjadi pasar yang homogen, segmentasi geografis merupakan suatu pendekatan untuk membagi pasar menjadi segmen-segmen berdasarkan lokasi, atas dasar bahwa orang-orang yang berasal dari wilayah atau wilayah yang sama memiliki kebutuhan yang sama, sehingga sampai batas tertentu pelanggan mungkin diharapkan datang.

Strategi Humas MAN 2 Tulungagung selanjutnya dalam pemasaran lembaga pendidikan yaitu memilih target sasaran (targeting). Menentukan target atau pasar sasaran perlu dilakukan, sebab tentunya lembaga pendidikan tidak bisa melayani seluruh pelanggan pendidikan dengan keadaan pelanggan yang tersebar dan keinginan yang bervariatif. Oleh sebab itu lembaga perlu mengevaluasi daya tarik masing-masing segmen dan memilih segmen pasar yang menarik untuk dilayani dengan banyaknya pelanggan pendidikan yang berasal dari segmen tersebut.

Adapun dalam pemilihan segmen sasaran atau target pemasaran humas MAN 2 Tulungagung memilih lembaga yang memiliki lulusan cukup baik dan berprestasi. Humas MAN 2 Tulungagung melakukan targeting dengan pola spesialisasi selektif yakni memilih lembaga-lembaga sekolah menengah dan sederajat di Kabupaten Tulungagung yang dipandang memiliki lulusan berkualitas antara lain SMP Negeri 1 Tulungagung, SMP Al Azhar Masjid Baitul Khoir, MTs Negeri 1 Tulungagung dan MTs Darunnajah. Spesialisasi selektif merupakan strategi yang dilakukan dimana lembaga pendidikan MAN 2 Tulungagung memilih sejumlah segmen pasar yang menarik dan sesuai dengan visi dan misi serta tujuan madrasah diantaranya mendapatkan calon siswa yang memiliki kualitas dan prestasi akademik yang baik sehingga bisa mengangkat mutu penyelenggaraan pendidikan di MAN 2 Tulungagung. Penentuan target (targeting) yang dilaksanakan oleh Humas MAN 2 Tulungagung berikutnya adalah memilih calon siswa baru dengan kualifikasi khusus antara lain kemampuan baca kitab fathul qorib dan hafidz Al Qur'an minimal 2 Juz. Hal ini dilakukan untuk mendukung program unggulan yang dilaksanakan di MAN 2 Tulungagung yakni pembelajaran Kitab Kuning dan Tahfidz Qur'an.

Strategi Humas MAN 2 Tulungagung dalam menentukan target atau sasaran dilakukan dengan dua pilihan yakni menjaring calon siswa dengan kualifikasi akademik yang baik dan kualifikasi khusus. Pengelompokan kualifikasi calon siswa baru ini dilakukan dengan mempertimbangkan keserasian visi dan program-program unggulan yang ditawarkan oleh MAN 2 Tulungagung. Penargetan merupakan klasifikasi dari kelompok yang memiliki berbagai kebutuhan yang sama dengan yang lain, dan kemudian sekolah menentukan satu sasaran layanan yang paling menonjol di lembaga yang sebelumnya telah dievaluasi oleh institusi sekolah sehingga mendapatkan hasil yang akurat (Widjaya, 2017). Penelitian Sidiq \& Na'imah, (2021) juga menggambarkan bahwa dari proses penargetan ini untuk mengetahui dan menggambarkan target pemasaran yang dibutuhkan oleh pengguna jasa pendidikan kebenaran bahwa suatu lembaga harus menentukan pelanggannya, agar dapat dilayani secara efektif di PG-TK Pelangi Ceria. Demikian juga penelitian yang dilakukan oleh Wright (2017) membuktikan bahwa penentuan target pelanggan secara khusus yang menjadi dukungan program unggulan di perguruan tinggi menjadi daya tarik tersendiri bagi masyarakat terhadap institusi tersebut.

Strategi Humas MAN 2 Tulungagung dalam kaitan pemasaran lembaga MAN 2 Tulungagung adalah penentuan posisi (positioning). Penentuan posisi pasar yaitu dimaksudkan dengan memposisikan keunggulan 


\section{Strategi Hubungan Masyarakat (Public Relation) dalam Peningkatan Pemasaran Lembaga Pendidikan - Suyitno \\ DOI: https://doi.org/10.31004/basicedu.v5i5.1480}

dan daya saing MAN 2 Tulungagung dibandingkan dengan lembaga lain yang berkenaan dengan upaya identifikasi, pengembangan, dan komunikasi keunggulan yang bersifat khas dan unik, sehingga produk atau jasa dipersepsikan lebih unggul dibandingkan produk atau jasa para pesaingnya.

MAN 2 Tulungagung memiliki 8 program madrasah. Program-program tersebut meliputi (1) kelas digital, (2) TIK dalam bidang pemrograman, (3) robotik, (4) tahfidz, (5) TOEFL, (6) program olimpiade, (7) program KIR, dan (8) olahraga dan seni. Kedelapan program tersebut merupakan wadah yang disediakan madrasah kepada peserta didik untuk mengasah kemampuan di bidang non akademik. Di antara kedelapan program unggulan tersebut, terdapat 6 program unggulan yang telah dilaksanakan oleh MAN 2 Tulungagung. Namun, kedepannya akan terus dilakukan perbaikan agar mendapatkan hasil yang lebih maksimal. Program TIK dalam bidang pemrograman meliputi (a) coding untuk aplikasi website dan (b) coding untuk mobile (animasi, game, desain grafis). Program teknologi lainnya yaitu, program robotik yang sejauh ini sudah mengukir prestasi untuk madrasah.

Program selanjutnya, yaitu program tahfidz. Program ini telah dikembangkan secara lebih luas lagi, dengan target yang diharapkan adalah, setiap lulusan MAN 2 Tulungagung memiliki bekal hafalan al Qur' an minimal 2 juz, khsususnya juz 30 dan 29. Pada program olimpiade dan program KIR, MAN 2 Tulungagung pun telah menunjukkan prestasinya, baik di KSN (Kompetisi Sains Nasional), maupun Mayres yang dilaksanakan oleh Direktorat KSKK Kemenag RI. Program unggulan yang akan dilaksanakan MAN 2 Tulungagung adalah program kelas digital dan TOEFL. Program kelas digital dibuat karena di era saat ini dimaksudkan agar siswa MAN 2 Tulungagung, untuk tidak gagap teknologi sedangkan program TOEFL dilaksanakan agar dapat menunjang siswa dalam melanjutkan ke jenjang perguruan tinggi selanjutnya. MAN 2 Tulungagung akan terus berbenah diri dengan terus mengevaluasi program yang ada sehingga dapat membimbing siswa dan menjadi wadah siswa untuk mengasah keahlian sehingga dapat mempertahankan prestasi bahkan menaikkan prestasi yang ada. Selain itu, MAN 2 Tulungagung juga akan mengembangkan diri dengan membuka program-program baru agar dapat bersaing dengan madrasah-madrasah lain.

Strategi Humas MAN 2 Tulungagung dalam positioning yaitu dengan mengkomunikasikan secara aktif secara internal maupun eksternal terkait dengan program-program unggulan dan prestasi-prestasi yang telah diraih. Komunikasi tersebut dimaksudkan sebagai upaya untuk membangun keunggulan lembaga baik dalam bidang akademik maupun non akademik serta menggerakkan sumber daya manusia yang ada untuk membantu terwujudnya keunggulan dan daya saing madrasah yang dapat meningkatkan pemasaran lembaga yaitu meningkatkan citra sekolah atau lembaga dengan menciptakan image yang bagus kepada publik, mampu menunjukkan keunggulan yang dimiliki lembaga, dan mampu menciptakan daya saing dengan perbedaan karakteristik yang dimiliki oleh MAN 2 Tulungagung dengan madrasah lain sebagai pesaing. Hal ini juga sesuai dengan hasil penelitian yang dilakukan oleh Melissa Rocio Gomez (2016); Paula (2019); Rajkumar et al. (2021) yaitu langkah-langkah strategis pemasaran institusi pendidikan salah satunya dengan diferensiasi produk yaitu dengan memberikan penawaran yang berbeda dibandingkan penawaran yang diberikan oleh kompetitor. Selain hal tersebut bidang humas juga berusaha mengembangkan keunggulan madrasah dan menciptakan brand image untuk dapat memberikan manfaat dari layanan jasa yang ditawarkan kepada pelanggan pendidikan yang sesuai dengan kebutuhan siswa dengan tujuan agar pelanggan merasa puas dan dapat menikmati manfaat dari layanan jasa yang ditawarkan. Hal ini sejalan dengan hasil penelitian Iqbal, (2016); Arifin et al., (2020) dan Fradito (2020) yang menyatakan publikasi akan mutu lulusan (output) yang unggul dan sesuai dengan profil lulusan dalam prestasi (akademik dan non akademik), terdepan dalam inovasi, maju dalam kreasi akan meningkatkan citra lembaga pendidikan yang akan meningkatkan kepercayaan dan loyalitas masyarakat. 
4144 Strategi Hubungan Masyarakat (Public Relation) dalam Peningkatan Pemasaran Lembaga Pendidikan - Suyitno

DOI: https://doi.org/10.31004/basicedu.v5i5.1480

\section{KESIMPULAN}

Berdasarkan pembahasan penelitian maka dapat disimpulkan beberapa hal penting, yang pertama Strategi humas MAN 2 Tulungagung dalam pemetaan pasar (segmentation) untuk meningkatkan pemasaran lembaga pendidikan dengan mempertimbangkan segmen emosional yang memprioritaskan dari aspek religiusitas dan ikatan alumni dan segmen geografis dengan menjangkau di dalam dan keluar daerah utamanya pondok-pondok pesantren besar dengan mempertimbangkan adanya persamaan pengembangan kurikulum tersebut dengan dengan program unggulan di MAN 2 Tulungagung. Kedua, strategi humas MAN 2 Tulungagung dalam penentuan target (targeting) untuk meningkatkan pemasaran lembaga pendidikan meliputi dilakukan dengan dua pilihan yakni dengan kualifikasi akademik yang baik dengan spesialisasi selektif untuk mendapatkan calon siswa yang memiliki prestasi akademik yang baik dengan dan kualifikasi khusus untuk menjaring calon siswa dengan kemampuan baca kitab fathul qorib dan hafidz Al Qur'an minimal 2 Juz. Ketiga, strategi humas MAN 2 Tulungagung dalam penentuan posisi pasar (positioning) untuk meningkatkan pemasaran lembaga pendidikan dengan memanfaatkan pendekatan penentuan pasar berdasarkan pesaing dengan membangun kepercayaan masyarakat dengan mempublikasikan deferensiasi program-program unggulan serta prestasi-prestasi yang diraih sehingga akan meningkatkan image dan citra madrasah.

\section{DAFTAR PUSTAKA}

Arifin, Z. A. L. S., Sumarwan, U., \& Najib, M. (2020). The Influence Of Marketing Mix On Brand Image, Motivation And Students Decision To Choose Graduate Studies Of Ipb University. Journal Of Consumer Sciences, 5(2), 139-156. Https://Doi.Org/10.29244/Jcs.5.2.139-156

Çoruk, A. (2018). School Principals' Opinions About Public Relations Practices On Schools. International Journal Of Progressive Education, 14(2), 136-147. Https://Doi.Org/10.29329/Ijpe.2018.139.10

Faridhoh, U., Muslihah, E., Kultsum, U., \& Gunawan, A. (2020). [No Title Found]. Tarbawi: Jurnal Keilmuan Manajemen Pendidikan, 6(02), 109. Https://Doi.Org/10.32678/Tarbawi.V6i02.2730

Fradito, A. (2020). Strategi Pemasaran Pendidikan Dalam Meningkatkan Citra Sekolah. Al-Idarah: Jurnal Kependidikan Islam, 10(1), 11.

Hemsley-Brown, J. (2016). Higher Education Market Segmentation. In J. C. Shin \& P. Teixeira (Eds.), Encyclopedia Of International Higher Education Systems And Institutions (Pp. 1-3). Springer Netherlands. Https://Doi.Org/10.1007/978-94-017-9553-1_33-1

Immelman, R., \& Roberts-Lombard, M. (2015). Guidelines For The Marketing Of Independent Schools In South Africa. Acta Commercii, 15(1), 9 Pages. Https://Doi.Org/10.4102/Ac.V15i1.245

Iqbal, S. (2016). Insights Of School Head About Marketing Education Services Through Digital Media. Journal Of Education And Educational Development, $3(1), \quad 52$. Https://Doi.Org/10.22555/Joeed.V3i1.711

Kartikasari, D. (2017). Market Segmentation Of Industry-Education Partnership Classes. Advances In Social Science, Education And Humanities Research, 128, 5.

Khan, A. (2017). Marketing For Business Education In India: Perspectives, Issues And Challenges. Global Journal Of Commerce \& Management Perspective, 6(6), 47-55. Https://Doi.Org/10.24105/Gjcmp.6.6.1708

Melissa Rocio Gomez. (2016). Marketing Strategies For Increasing Latino Enrollment In Higher Education. Walden University, Walden Dissertations And Doctoral Studies Collection, 119.

P, H. A., \& Andriyani, D. E. (2020). Public Relations Management In Building The Image Of Schools In Senior High School. Journal of The Community Development In Asia, 3(3), 1-6. Https://Doi.Org/10.32535/Jcda.V3i3.885 
4145 Strategi Hubungan Masyarakat (Public Relation) dalam Peningkatan Pemasaran Lembaga Pendidikan - Suyitno

DOI: https://doi.org/10.31004/basicedu.v5i5.1480

Paula, A. I. (2019). Educational Marketing Strategies On The Market Of Higher Education Services. People: International Journal Of Social Sciences, $\quad 5(3), \quad 334-344$. Https://Doi.Org/10.20319/Pijss.2019.53.334344

Rajkumar, S. G., Joseph, D. C. S., \& Sudhakar, D. J. C. (2021). Digital Marketing Communication Strategies And Its Impact On Student Higher Education Decision Making Process - A Review Of Relevant Academic Literature. Psychology And Education, 13.

Salinan Ppdb 2017.Pdf. (N.D.).

Sidiq, A. M., \& Na'imah, N. (2021). Marketing Of Paud Services In The Pandemic Period In Pg-Tk Pelangi Ceria (Based On Sementation, Positioning, And Targeting). Nidhomul Haq: Jurnal Manajemen Pendidikan Islam, 6(1), 1-13. Https://Doi.Org/10.31538/Ndh.V6i1.1137

Suyitno. (2018). Metode Penelitian Kualitatif: Konsep, Prinsip Dan Operasionalnya (1st Ed.). Akademia PustakaTulungagung. Https://Www.Researchgate.Net/Publication/326957100_Metode_Penelitian_Kualitatif_Konsep_Prinsip _Dan_Operasionalnya

Wardaya, M. (2016). Marketing Communication Strategy Through Social Media To Increase Children Book Sales. The Winners, 17(2), 155. Https://Doi.Org/10.21512/Tw.V17i2.1975

Widjaya, P. G. (2017). Analisis Segmenting, Targeting, Positioning Dan Marketing Mix Pada Pt.Murni Jaya. Agora, 5(1), 8.

Wright, R. E. (2017). Targeting A New Customer Segment: Marketing Of Higher Education Through Athletics. Journal Of Applied Business And Economics, 19(6), 106-110. 